\title{
Occurrence of a late response to exercise in asthmatic children: multiple regression approach using time-matched baseline and histamine control days
}

\author{
W.B. Hofstra*, P.J. Sterk**, H.J. Neijens ${ }^{+}$, J.M. Kouwenberg*, \\ P.G.H. Mulder ${ }^{++}$, E.J. Duiverman*
}

Occurrence of a late response to exercise in asthmatic children: multiple regression approach using time-matched baseline and histamine control days. W.B. Hofstra, P.J. Sterk, H.J. Neijens, J.M. Kouwenberg, P.G.H. Mulder, E.J. Duiverman. CERS Journals Ltd 1996.

ABSTRACT: At the present time, there is still controversy concerning the presence of a late asthmatic response (LAR) to exercise challenge in asthma. We have, therefore, investigated the occurrence of a LAR after exercise in asthmatic children visiting an out-patient clinic, using time-matched baseline and histamine control days, and a statistical analysis according to recently published recommendations.

After a screening exercise day, 17 children (aged 7-14 yrs) randomly performed, on three subsequent study days, either: a second standardized exercise challenge; or a histamine challenge whilst matching the bronchoconstriction after exercise; or measurement of baseline lung function without any challenge. Measurements of forced expiratory volume in one second (FEV1) were made repeatedly during $8 \mathbf{h}$. Analysis was performed using multiple regression analysis for each patient, with FEV1 as the dependent, and test day (exercise or control) and clock time as independent variables during the period $2-8 \mathrm{~h}$ after exercise. A significant interaction $(p<0.05)$ between test day and clock time was considered to be indicative of a LAR.

Fifteen children completed the study. All children showed an early asthmatic reaction to exercise (range 14-62\% fall in FEV1). In two children, a significant interaction $(p<0.05)$ was found between test day and clock time. However, the difference in FEV1 between exercise and control days for each clock time did not exceed the $\mathbf{9 9 . 6 \%}$ confidence limits of normal diurnal variation in any of the children.

We conclude that, in children with mild-to-moderate asthma, a LAR to exercise does not occur. This suggests that exercise is only a symptomatic trigger of asthma. Whether exercise is capable of inducing inflammation needs to be further investigated.

Eur Respir J., 1996, 9, 1348-1355.
*Dept of Pulmonary Pediatrics, Juliana Childrens' Hospital, The Hague, The Netherlands. **Dept of Pulmonary Diseases, Leiden University Hospital, Leiden, The Netherlands. +Sophia Childrens' Hospital, Rotterdam, The Netherlands. ${ }^{++}$Dept of Epidemiology and Biostatistics, Erasmus University Medical School, Rotterdam, The Netherlands.

Correspondence: W.B. Hofstra

Juliana Childrens' Hospital

Dr van Welylaan 2

2566 ER The Hague

The Netherlands

Keywords: Bronchial hyperresponsiveness childhood asthma

statistical method

Received: August 81995

Accepted after revision January 201996
It has long been recognized that exercise can induce acute bronchoconstriction in patients with asthma [1], the so-called exercise-induced bronchoconstriction (EIB). In childhood asthma, the prevalence of EIB ranges 70-90\% $[2,3]$. Children suffering from EIB may complain about any of the following symptoms during or after strenuous exercise: wheezing, shortness of breath, cough or chest pain $[4,5]$. The bronchoconstrictor response to exercise is determined by the level of ventilation reached during exercise, as well as the temperature and water content of the inspired air [6]. The precise mechanism by which EIB occurs is still a matter of debate. However, studies with mediator antagonists and synthesis inhibitors have provided supportive evidence for the release of mediators, such as histamine, prostaglandins and leukotrienes, during the early asthmatic response (EAR) after exercise [7, 8].

Since its first description in 1980 [9], there has been considerable controversy in the literature on the potential development of a late asthmatic response (LAR) to exercise in asthma. It is known that the occurrence of a LAR after allergen challenge is associated with an influx of inflammatory cells and the development of bronchial hyperresponsiveness [10]. Therefore, if a LAR after exercise does exist, it could have important consequences for our understanding of the pathophysiological mechanisms of EIB, and consequently for the therapy of asthma.

A number of studies have been published describing the occurrence of a LAR after exercise with prevalence ranging 10-89\% [11-17]. However, nearly as many studies have been unable to document a LAR [18-23]. The experimental design of some of the studies showing a LAR has been criticized because of the lack of "appropriate" control days [24], during which lung function is being documented without exercise or following bronchoconstriction induced by inhaled histamine. Furthermore, when evaluating the results of these studies, there seems 
to be considerable lack of agreement among the various investigators on the definition of the LAR after exercise. The LAR has been defined as either a $10 \%[12,15]$, $15 \%[14,20,23]$ or $20 \%[16,17,19,21]$, fall in lung function $(e . g$. the forced expiratory volume in one second (FEV1)) during different time-periods after exercise challenge. However, the definition according to a fixed percentage fall in FEV1 carries the risk of a false-negative or a false-positive diagnosis, because it does not take into account normal diurnal variation in lung function in the asthmatic subjects.

Recently, a paper has been published in this Journal describing statistical methods for the identification of a LAR in individual subjects [25], using serial hourly measurements of lung function on several control days. The aim of this analysis was to interpret challenges with allergens or occupational sensitizers more sensitively [25], by taking into account individual day-to-day variability in pulmonary function on control days. In the present study, we have therefore applied an analogous approach, using multiple linear regression analysis for each patient, to evaluate the occurrence of LAR after exercise in a group of asthmatic children. To that end, we repeatedly measured lung function up to $8 \mathrm{~h}$ after exercise challenge. We also measured lung function during a control day without exercise (negative control), and on a day after histamine challenge inducing a matched level of bronchoconstriction to that observed after exercise (positive control).

\section{Methods}

\section{Patients}

Seventeen children ( 8 males and 9 females) were recruited from the out-patient clinic of the Department of
Pediatric Pulmonology of the Juliana Childrens' Hospital in The Hague (table 1). They were all known already at the clinic and had a diagnosis of asthma [26]. All had a history of exercise-induced bronchoconstriction and showed a fall in FEV1 $>10 \%$ as compared to pre-exercise FEV1 after a standardized screening exercise challenge. Mean age of the children was 10 yrs (range 7-14 yrs) and at screening their baseline FEV1 was $>75 \%$ of predicted value [27]. All children except two were atopic (radioallergosorbant test (RAST) class $\geq 2$ for at least one inhalant allergen).

All children were clinically stable (i.e. no history of exacerbation and/or respiratory viral infection during the 2 weeks before entry into the study). Anti-inflammatory maintenance treatment was reduced according to a standardized protocol. Sodium cromoglycate (3 out of 17) and the anti-histamine cetirizine ( 2 out of 17 ) were stopped 2 weeks before the first study day. The dose of inhaled corticosteroids (7 out of 17) was halved for the first week and, thereafter, tapered by $100 \mu \mathrm{g}$ each week, until no inhaled steroids had been used in the week before the first study day. Inhaled short-acting bronchodilators were used as rescue medication during the study period. No bronchodilatory therapy was used for at least $8 \mathrm{~h}$ before each study day.

Informed consent was obtained in all cases. The study was approved by the Local Hospital Medical Ethics Committee.

\section{Study design}

All practical work was performed at the Juliana Childrens' Hospital in The Hague. The children attended the lung function laboratory on four consecutive days at intervals of at least $24 \mathrm{~h}$ and within a study period of 3 weeks.

Table 1. - Patient characteristics

\begin{tabular}{|c|c|c|c|c|c|c|c|c|c|}
\hline $\begin{array}{l}\mathrm{Pt} \\
\text { No. }\end{array}$ & Sex & $\begin{array}{r}\text { Age } \\
\text { yrs }\end{array}$ & Atopy & EX1 & $\begin{array}{l}\text { Baseline FEV1 } \\
\text { EX2 }\end{array}$ & $\begin{array}{l}\% \text { pred }^{\#} \\
\mathrm{H}\end{array}$ & $\mathrm{C}$ & $\begin{array}{c}\text { PD20 } \\
\mu \mathrm{g}\end{array}$ & Therapy ${ }^{\dagger}$ \\
\hline 1 & M & 7 & + & 94 & 92 & 92 & 96 & 120 & salb \\
\hline 2 & M & 8 & + & 108 & 102 & 104 & 102 & 30 & sdcg \\
\hline 3 & $\mathrm{~F}$ & 12 & + & 91 & 95 & 97 & 90 & 36 & bdp \\
\hline 4 & F & 11 & + & 105 & 107 & 107 & 112 & 55 & bdp \\
\hline 5 & $\mathrm{M}$ & 10 & + & 98 & 91 & 94 & 93 & 55 & salb \\
\hline 6 & $\mathrm{~F}$ & 9 & + & 82 & 91 & 89 & 85 & 20 & bdp \\
\hline 7 & M & 14 & + & 83 & 80 & 79 & 89 & 4 & bud \\
\hline 8 & $\mathrm{~F}$ & 10 & + & 99 & 98 & 101 & 101 & 23 & bdp \\
\hline 9 & $\mathrm{~F}$ & 12 & - & 113 & 113 & 103 & 112 & 31 & salb \\
\hline 10 & $\mathrm{~F}$ & 11 & + & 93 & 98 & 91 & 97 & 40 & salb \\
\hline 11 & F & 10 & + & 85 & 85 & 86 & 86 & 9.2 & cet \\
\hline 12 & F & 7 & + & 103 & 97 & 99 & 99 & 11 & sdcg \\
\hline 13 & M & 11 & + & 102 & 103 & 102 & 101 & 90 & bdp \\
\hline 14 & M & 9 & + & 85 & 84 & 79 & 79 & 28 & salb \\
\hline 15 & $\mathrm{~F}$ & 7 & - & 85 & - & - & 94 & 7.6 & salb \\
\hline 16 & M & 7 & + & 97 & - & - & 95 & 5.5 & cet,bdp \\
\hline 17 & M & 10 & + & 87 & 82 & 81 & 77 & 28 & sdcg \\
\hline Mean & & 9.7 & & 95 & 95 & 94 & 95 & $24 \%$ & \\
\hline$\pm \mathrm{SD}$ & & 2.0 & & 10 & 9 & 9 & 11 & $1.4 \ddagger$ & \\
\hline
\end{tabular}

\#: FEV1 at start of study day expressed as percentage of predicted FEV1 ( $\%$ pred); ${ }^{\dagger}:$ therapy before standardized cessation of regular treatment; $\ddagger$ :geometric mean \pm sD in doubling doses. Pt: patient; M: male; F: female; FEV1: forced expiratory volume in one second; EX1: exercise screening day; EX2: second exercise challenge day; $\mathrm{H}$ : histamine inhalation day; $\mathrm{C}$ : control day, lung function measurement in absence of challenge; PD20: provocative dose of histamine causing a 20\% fall in FEV1; salb: salbutamol; cet: cetirizine; sdcg: sodium dicromoglycate; bdp: beclomethasone dipropionate; bud: budesonide. 
On the first day (exercise screening day $=$ EX1-day) baseline FEV1 was measured in triplicate followed by standardized exercise challenge. Lung function measurements (FEV1) were made repeatedly during the recovery period, and thereafter every $30 \mathrm{~min}$ up to $8 \mathrm{~h}$ after challenge. On the subsequent three study days, in random order, either: a second exercise challenge (EX2-day) was performed; or a histamine inhalation challenge (H-day) matching the degree of bronchoconstriction after the screening exercise; or lung function measurements were performed in the absence of challenge (C-day), again during the same $8 \mathrm{~h}$ period. On each of the four study days, individual children started at the same time of day, usually 9.00 a.m. During the study days, the children stayed in one of the rooms of the lung function laboratory abstaining from strenuous exercise.

\section{Lung function measurements}

For each individual child, lung function measurements were made either using a dry rolling-seal spirometer (Vicatest 5; Mijnhardt, The Netherlands) or a pneumotachograph (Flowscreen; Jaeger, Germany). Only one device was used for each child. The highest FEV1 obtained from three forced expiratory manoeuvres at each timepoint was retained for analysis [28].

\section{Exercise challenge (EX-days)}

Exercise challenge was performed by running on a treadmill (LE 2000; Jaeger, Germany) for 6 min [29]. During the test, heart rate was checked using a heart rate monitor (Polar Sporttester). The children started at walking pace on the treadmill for $1 \mathrm{~min}$. Thereafter, the speed of the treadmill was increased to induce a heart rate of at least $90 \%$ of the maximum predicted heart rate for each individual child (maximum heart rate $=210$ - age in years). Knowing that the occurrence of a LAR may be dependent upon the severity of the early asthmatic response (EAR) to exercise [13], and knowing that the severity of the EAR to exercise is aggravated when the humidity of the inspired air during exercise is decreased [30], dry air was used to increase the osmotic stress to the airways in order to augment the EAR. This dry air (relative humidity $<15 \%$ ) was inspired from a reservoir bag through a face mask with an inspiratory and expiratory port (Speak Easy II) during running. Using this protocol in our laboratory, the intraclass correlation coefficient for repeatability of the bronchoconstrictor response (expressed as percentage fall in FEV1) is 0.57 [31]. Dry air was not used when a preliminary exercise challenge had already shown severe obstruction (percentage fall in FEV $1>45 \%)$ when breathing room air $(n=3)$, or in case of fear of the mask $(n=1)$. Lung function measurements were made in triplicate before exercise as well as $1,3,5,7,10,15,20,25$ and 30 min afterwards, and then every $10-15 \mathrm{~min}$, until $2 \mathrm{~h}$ after challenge. Thereafter, lung function measurements were made every $30 \mathrm{~min}$ up to $8 \mathrm{~h}$ after exercise, allowing the calculation of the EAR and the LAR to exercise.

\section{Histamine challenge (H-day)}

A standardized dosimetric technique was used to perform the histamine challenge [32]. A Rosenthal-French dosimeter was connected to a Devilbiss nebulizer type 646. By slow inhalation from functional residual capacity (FRC) to total lung capacity (TLC), the dosimeter was triggered to deliver a dose of histamine to the mouth. Starting with the lowest dose of histamine diphosphate in physiological saline, doubling doses $(5-640 \mu \mathrm{g})$ were then inhaled. Three minutes after inhaling each dose of histamine, FEV1 was measured in triplicate, the highest FEV1 being used in the analysis. The histamine challenge ended if the percentage fall in FEV1 from baseline did not differ by more than $10 \%$ from the percentage fall in FEV1 as induced by the first exercise test on EX1day for each individual child.

During spontaneous recovery from the bronchoconstriction to histamine, FEV1 measurements were repeated in triplicate at the same time intervals as used after exercise challenge up to $8 \mathrm{~h}$. This allowed the calculation of the EAR to histamine in the same way as used for exercise. To assess bronchial responsiveness to histamine, the provocative dose of histamine causing a $20 \%$ fall in FEV1 (PD20 histamine) was determined by linear interpolation between two data points on the noncumulative log dose-response curve [32].

\section{Control day (C-day)}

On the control day without any challenge, the FEV1 measurements were performed in triplicate every $15 \mathrm{~min}$ during the first $2 \mathrm{~h}$, and thereafter repeated every $30 \mathrm{~min}$ until lung function measurements had been recorded during a time-period of $8 \mathrm{~h}$.

\section{Analysis}

For analysis, EX2-day was taken as the active challenge day, while FEV1 measurements both of C-day and $\mathrm{H}$-day served as control values. The use of histamine as a positive control challenge was based on the assumption that a LAR does not occur after histamine challenge in the time-period studied [33]. Study days were only used for analysis if FEV1 (expressed as percentage predicted) at the start of the active challenge days and the control days did not differ by more than $10 \%$.

\section{Early asthmatic response to exercise and histamine}

The EAR to exercise or histamine was expressed as maximal percentage fall in $\mathrm{FEV} 1$ from prechallenge baseline value during the first hour, according to:

$$
\mathrm{EAR}=\frac{\text { prechallenge FEV1-lowest FEV1 first hour }}{\text { pre-challenge FEV1 }} \times 100 \%
$$

The EAR to exercise and histamine were compared using Students' t-test of paired samples. 
Results

To identify a LAR after exercise, multiple regression analysis [34] for each patient was applied based on the half-hourly FEV1 measurements in the time-period 2-8 h postexercise. FEV1 was taken as the dependent variable, with day (exercise or control) and clock time (of FEV1 measurement) as independent variables. In a first fitted regression model, only the main effects of day and clock time were evaluated, the effect of day for each patient being the difference in lung function between exercise day and control days, at each clock time. Multiple linear regression analysis automatically provides the proper t-test for this effect within each patient. However, in the presence of a LAR, a difference in lung function should vary with time of day.

Therefore, in a second step, the regression model was extended with the interaction variable of day and clock time. Again, multiple linear regression analysis automatically provides the proper F-test. If a statistically significant $(\mathrm{p}<0.05)$ interaction was found in an individual patient, the standard error of the difference between exercise day and control days as estimated in the second regression model, was used to calculate a $100^{*}\left(0.95^{1 / 13}\right)=$ $99.6 \%$ confidence interval for this difference (Bonferroni correction). To verify the occurrence of a LAR, a graphic representation of the difference in lung function between the exercise day and the control days for each clock time was drawn, together with its $99.6 \%$ confidence interval. For a LAR to be present, at least two consecutive time-points had to lie outside the confidence interval.

The analysis was performed using the absolute value (L) of the FEV1 measurements at each time-point as well as the values expressed as percentage of baseline FEV1 at the start of the study day.
Thirteen children completed all four study days, and in an additional two children data were available on at least one exercise day and both control days. Two children completed two study days only, due to clinical deterioration of their asthma requiring therapeutic intervention, and they were excluded from analysis. There was no significant difference in baseline FEV 1 between the exercise and the control days (mean difference \pm SD between EX2 day and H-day: $1.07 \pm 4.3 \%$ predicted $(\mathrm{p}=0.29)$; between EX2-day and C-day: $0.07 \pm 4.3 \%$ pred, $(\mathrm{p}=0.95)$ ). Twelve out of 17 children did not run for the full $6 \mathrm{~min}$ because of discomfort associated with wheezing during running. The duration of the exercise test for these children ranged 3.5-5.5 min. Room temperature varied from $19-25^{\circ} \mathrm{C}$, depending on the season. Within the study period of an individual child, room temperature did not vary more than $2^{\circ} \mathrm{C}$. Relative humidity of the dry air ranged $4.5-9 \%$.

\section{Early asthmatic reaction}

Maximal percentage fall in FEV1 during the first hour after exercise or after histamine challenge is shown in table 2. Differences in mean percentage fall in FEV1 between the challenges were not statistically significant (mean EAR \pm SD after EX1: $40 \pm 16 \%$ fall; after EX2: $38 \pm 15 \%$ fall; and after histamine: $41 \pm 11 \%$ fall; $p>0.05$ ) (fig. 1 ).

\section{Late asthmatic reaction}

Table 2 also shows the individual results of the multiple regression analysis over the period $2-8 \mathrm{~h}$ postexercise.

Table 2. - Early asthmatic response (EAR) after exercise and histamine challenge and the occurrence of a LAR

\begin{tabular}{|c|c|c|c|c|c|c|c|}
\hline \multirow[t]{2}{*}{$\begin{array}{l}\text { Pt } \\
\text { No. }\end{array}$} & \multicolumn{3}{|c|}{$\begin{array}{c}\text { EAR } \\
\% \text { fall in FEV } 1\end{array}$} & \multirow{2}{*}{$\begin{array}{c}\text { Effect of day\# } \\
\text { on FEV1 } \\
\text { L }\end{array}$} & \multirow{2}{*}{$\begin{array}{l}\text { p-value }{ }^{\dagger} \\
\text { interaction } \\
\text { effect }\end{array}$} & \multirow{2}{*}{$\begin{array}{c}\text { Effect of day\# } \\
\text { on FEV } 1 \\
\% \text { baseline }\end{array}$} & \multirow{2}{*}{$\begin{array}{l}\text { p-value }^{\dagger} \\
\text { interaction } \\
\text { effect }\end{array}$} \\
\hline & EX1 & EX2 & $\mathrm{H}$ & & & & \\
\hline 1 & 14 & 14 & 25 & $-0.084 *$ & 0.94 & $-3.54 *$ & 0.42 \\
\hline 2 & 16 & 34 & 35 & $-0.077 *$ & 0.072 & $-3.12 *$ & 0.017 \\
\hline 3 & 24 & 18 & 25 & $+0.126^{*}$ & 0.99 & $+5.35^{*}$ & 0.99 \\
\hline 4 & 25 & 35 & 28 & $-0.052^{*}$ & 0.58 & -0.35 & 0.99 \\
\hline 5 & 28 & 20 & 35 & -0.020 & 1.0 & +1.62 & 1.0 \\
\hline 6 & 34 & 37 & 38 & +0.029 & 0.12 & $-2.65^{*}$ & 0.10 \\
\hline 7 & 35 & 48 & 53 & $-0.229 *$ & 0.84 & -3.79 & 0.87 \\
\hline 8 & 40 & 48 & 39 & +0.027 & 0.56 & +1.38 & 0.96 \\
\hline 9 & 41 & 27 & 40 & +0.009 & 0.60 & $-5.08 *$ & 0.84 \\
\hline 10 & 53 & 62 & 49 & $-0.118^{*}$ & 0.88 & $-8.70^{*}$ & 0.10 \\
\hline 11 & 54 & 53 & 39 & $+0.087 *$ & 0.80 & $+6.27 *$ & 0.76 \\
\hline 12 & 55 & 30 & 41 & -0.009 & 0.68 & +1.04 & 0.56 \\
\hline 13 & 58 & 32 & 60 & $-0.089 *$ & 0.049 & $-5.40 *$ & 0.040 \\
\hline 14 & 58 & 54 & 53 & $+0.104 *$ & 0.92 & +1.10 & 0.94 \\
\hline 17 & 61 & 57 & 54 & $+0.223 *$ & 0.38 & $+8.83^{*}$ & 0.55 \\
\hline Mean & 40 & 38 & 41 & & & & \\
\hline$\pm \mathrm{SD}$ & 16 & 15 & 11 & & & & \\
\hline
\end{tabular}

The results of the analysis is represented in two parts, with the effect of day only (first step), and the interaction effect of day and time shown separately. \#: effect of day, i.e. difference in FEV1 between EX2-day and mean of control days, for given time of the day, as evaluated in the first step of the analysis; *: $\mathrm{p}<0.05$ for main effect of day only; ${ }^{\dagger}$ : p-value of the interaction effect between day and time in the second step of the analysis. For definitions see legend to table 1. 


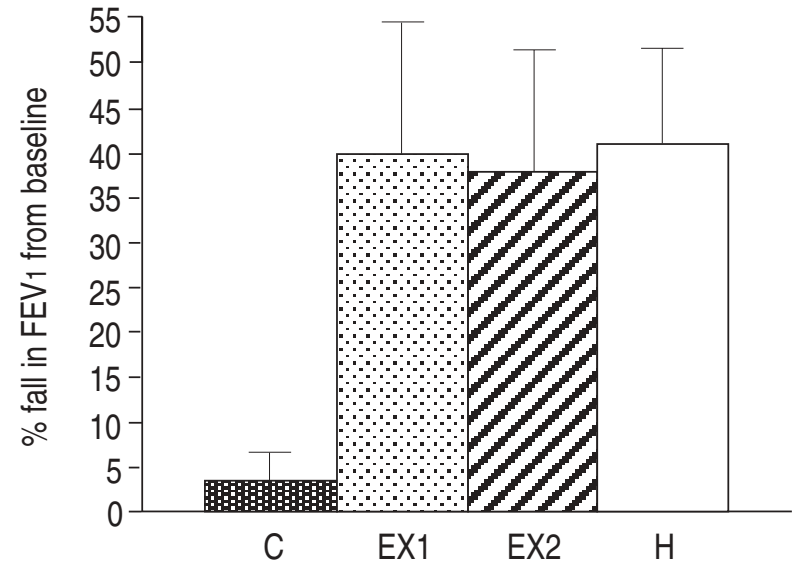

Fig. 1. - Mean $( \pm \mathrm{SD})$ percentage fall in FEV1 from baseline value during the first hour for EX1-, EX2-, H- and C-day. FEV1: forced expiratory volume in one second; EX1: exercise screening day; EX2: second exercise challenge day; $\mathrm{H}$ : histamine inhalation day; C: control day, lung function measurement in absence of challenge.

a)

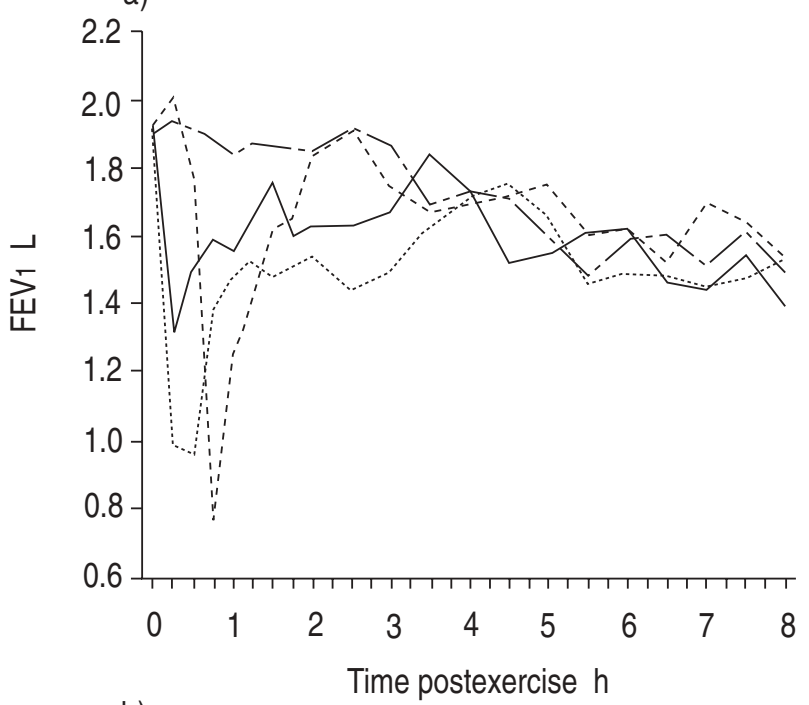

b)

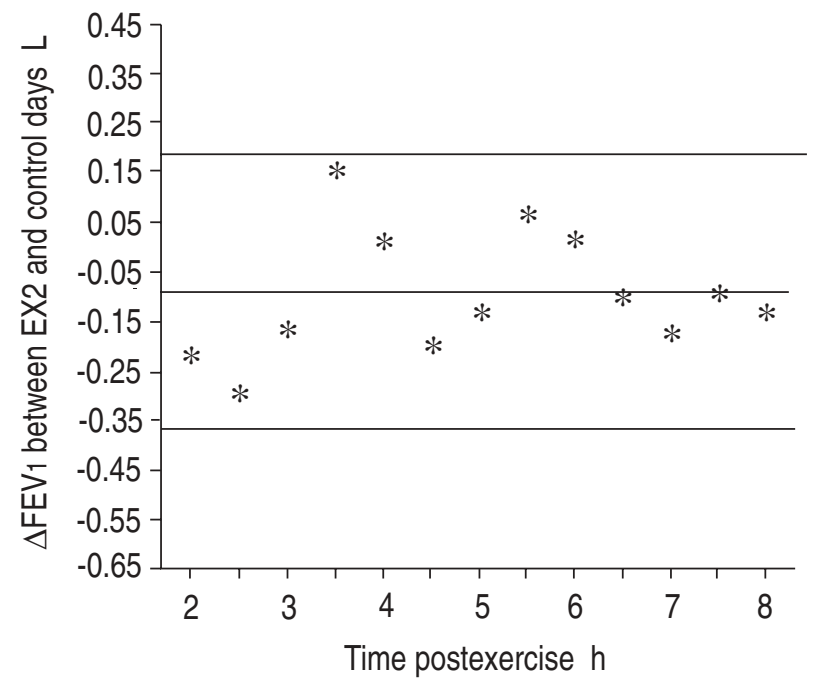

Fig. 2. - a) Lung function measurements (FEV1) during four study days in child No. 13. ......... : EX1-day; — : EX2-day; - - - : Cday; ..... : H-day. b) Difference in FEV1 $\left(\triangle \mathrm{FEV}_{1}\right)$ between EX2 and control days for each time of the day, with the $99.6 \%$ confidence interval, in child No. 13. For definitions see legend to figure 1.
The effect of day on FEV1 in this analysis as estimated from the first step (main effects only) is shown for each child. In 10 out of 15 children the difference in FEV1 between EX2-day and control days, although small, was statistically significant, with FEV1 either being lower $(n=6)$ or higher $(n=4)$ on the active challenge day as compared to control days, for given time of the day. The next column in table 2 shows the results of the second step in the analysis, in which the interaction effect between day and clock time is evaluated. When this analysis was performed using absolute values of FEV1, a statistically significant interaction effect indicative of a potential LAR was found in only 1 child (No. 13). Repeating the analysis using FEV1 expressed as percentage of baseline resulted in one additional child (No. 2) showing a potential LAR. In figures $2 \mathrm{a}$ and $3 \mathrm{a}$, respectively, the lung function of these two children during the four study days is represented, whilst in figures $2 \mathrm{~b}$ and $3 \mathrm{~b}$, respectively, a graphical representation of the difference in FEV1 measurements between EX2-day and control days for these

a)
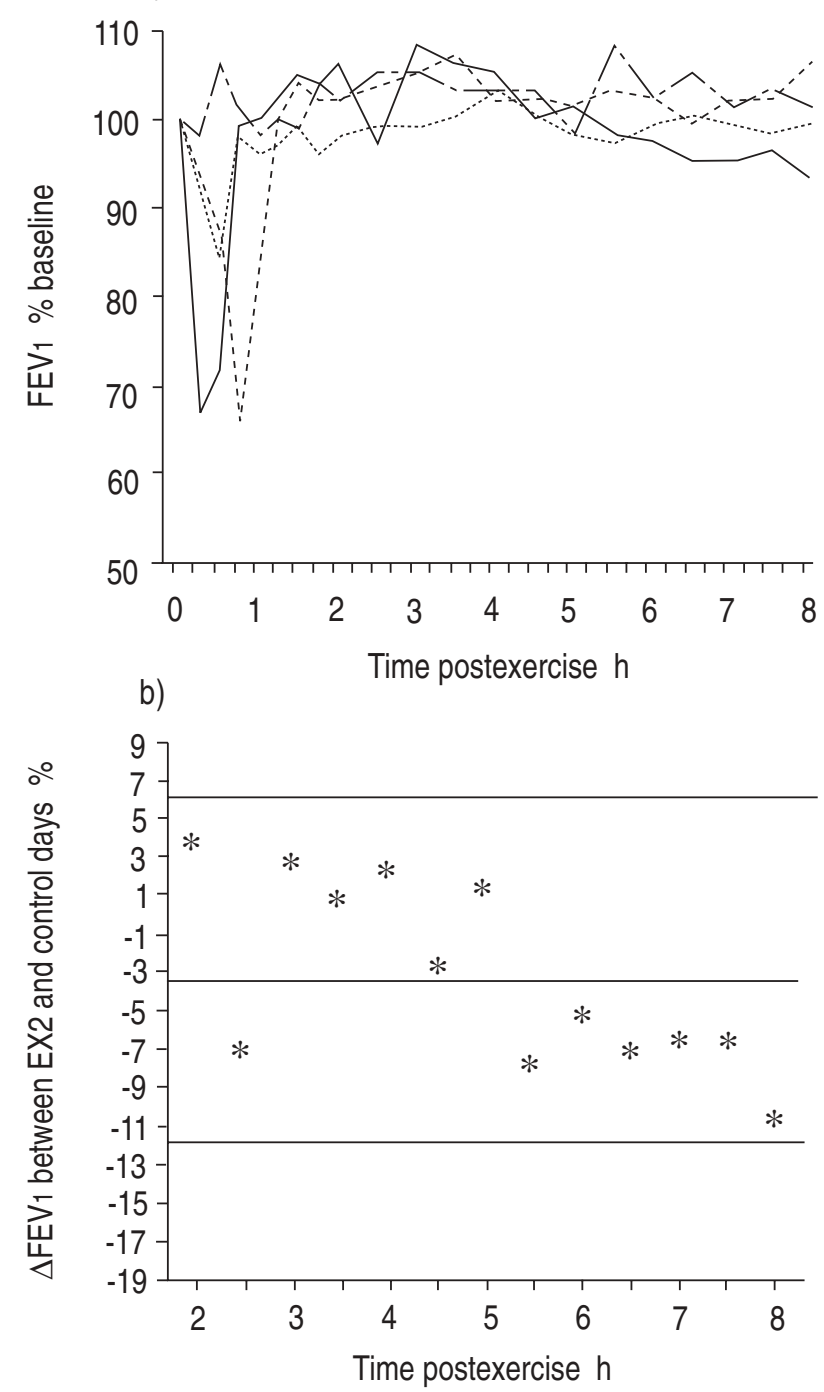

Fig. 3. - a) Lung function measurements (FEV $1 \%$ baseline) during four study days in child No. 2. ….... : EX1-day; _ : EX2-day; - - : C-day; - - - : : H-day. b) Difference in FEV $1\left(\triangle \mathrm{FEV}_{1}\right)$ between EX2 and control days for each time of the day, with the $99.6 \%$ confidence interval, in child No. 2. For definitions see legend to figure 1. 
two children is given together with its $99.6 \%$ confidence interval. As can be seen from these figures, for both children, all differences in FEV1 measurements between EX2-day and control days from $2-8 \mathrm{~h}$ postexercise are within the confidence interval.

\section{Discussion}

In this study, we have shown the absence of a late asthmatic response to exercise in children with mild-to-moderate asthma visiting an out-patient clinic. All children suffered an early asthmatic response to exercise. To identify a LAR accurately, and to take into account individual variability of diurnal variation in lung function, a statistical method was applied using multiple regression analysis for each patient, based on serial lung function measurements after exercise challenge and during a positive and negative control day. These data indicate that exercise, unlike allergens, is merely a symptomatic, and not a causative trigger of asthma [35] leading to obstruction but not to induction of inflammation.

This is not the first study of the occurrence of a LAR after exercise in asthmatic subjects. The results presented are in agreement with those of RUBINSTEIN et al. [19] and of BONER and co-workers [23]. In contrast, other investigators have described the existence of a LAR after exercise in asthmatic children $[11,13,16]$. When comparing the results of our study with those published, a number of methodological points need to be addressed.

Firstly, the selection of the population studied may be important. In our study, the children were treated for their asthma at an out-patient clinic. Other investigators have used a study group of asthmatic children, resident at special asthma clinics $[16,23]$. It could be argued that the latter population may have suffered from more severe and uncontrollable asthma, which is often the reason for referral to specialized clinics.

Secondly, the exercise provocation method may have influenced the results. In our study, as opposed to others, most children (13 out of 17) breathed dry air during running. Even though inspired dry air is currently the method of choice [36], we did not use this potentially strong stimulus in three children who already showed severe bronchoconstriction when inhaling room air. One could argue that this could mean a difference in the exercise stimulus applied. However, as the fall in FEV1 postexercise is proportional to the total amount of water lost from the airways [37], we do not think that this has influenced our results, as long as the stimulus remains constant within subjects.

Thirdly, and perhaps more importantly, the designs of the different studies of the LAR after exercise merit special consideration. Among the 13 studies cited [11-23], only four used randomized study days [16, 20-22]. The choice of "adequate" control days to establish normal diurnal variation in lung function can be considered to be of vital importance [24]. Measurements of spontaneous variations in lung function have to be made both after another nonspecific challenge, e.g. histamine or methacholine, and during a day without any bronchial challenge. The importance of using adequate control days is illustrated by two studies of BONER et al. [14, 23]. In the first study [14], only one negative control day was used and prevalence of a LAR after exercise was found to be $26 \%$. However, when the study was repeated using multiple control days to account for normal diurnal variation in lung function, the occurrence of a LAR after exercise could no longer be confirmed [23]. Even though, in the latter study, lung function measurements were performed both on a negative and a positive control day, the present study is the only one in which the bronchoconstriction induced by histamine was carefully matched for degree of bronchoconstriction after exercise.

Finally, there is considerable lack of agreement among the various investigators about the analysis of a potential LAR. For instance, it has not been clarified during which time-period a LAR after exercise might occur. In addition, most authors define the LAR according to a predetermined percentage fall in lung function, either from prechallenge value $[12,14,15,19-21]$, or as compared to lung function measured at an identical timepoint on a control day $[13,17,23]$. However, these methods are somewhat arbitrary. They carry the risk of a false-positive diagnosis in a subject with considerable spontaneous variability of ventilatory function, or, similarly, the risk of a false-negative diagnosis if spontaneous variability is low. To eliminate the potential confounding effect of day-to-day variability in pulmonary function when identifying a LAR, the use of statistical tests has recently been advocated to quantify normal diurnal variation [25], thereby allowing recognition of a LAR after challenge with greater precision. Therefore, we have used multiple regression analysis within each patient, taking into account normal diurnal variation on a positive and a negative control day, to optimize the identification of a LAR after exercise in the patient group studied.

How can the present results be interpreted? Our results show that in out-patients with childhood asthma, in stable conditions, avoiding antiasthma drugs, a LAR after exercise challenge is absent. This contrasts to allergen provocation, after which a LAR occurs in $50-75 \%$ of asthmatics challenged [38]. During the allergen-induced late phase reactions, an influx of eosinophils into the bronchial system has been observed [39], also reflected in an increase in serum eosinophil cationic protein (sECP) [40]. The occurrence of a postallergen LAR has also been associated with an increase in bronchial hyperresponsiveness to histamine, while the absence has not [41]. During the early asthmatic reaction after exercise, the different mediators released, such as histamine, prostaglandins and leukotrienes [7, 8], resemble those released during the EAR after allergen challenge [42]. However, the absence of a postexercise LAR indicates that exercise appears not to induce an inflammatory process, which is indirectly supported by the observation that bronchial hyperresponsiveness to histamine is not increased after exercise provocation [23], as opposed to allergen challenge [43].

What is the clinical significance of these data? Firstly, in the absence of a LAR after exercise, one could argue that it would suffice to treat patients with asthma symptoms occurring only after exercise symptomatically, e.g. with a short-acting bronchodilator [44], disodium cromoglycate or nedocromil [45]. However, it should be remembered that the symptom of EIB in asthma should be interpreted as a sign of bronchial hyperresponsiveness 
[35]. It has been known for many years that the severity of EIB is moderately correlated to the severity of methacholine-induced hyperresponsiveness [46]. In the current concept of asthma as an inflammatory disease, there are many studies linking bronchial hyperresponsiveness to inflammatory changes in the airways. Therefore, we think it valid to consider regular anti-inflammatory therapy in those patients with moderate to severe EIB [47].

In conclusion, we have shown the absence of a late asthmatic response after exercise in childhood asthma. This supports the concept of exercise being a symptomatic trigger, and thus a reflection of bronchial hyperresponsiveness, instead of a causative factor in asthma. However, more studies are needed in asthmatic children to investigate the relationship between bronchial hyperresponsiveness, exercise-induced bronchoconstriction and inflammatory changes in the airways.

Acknowledgements: The authors wish to thank the Medical Department of Glaxo BV and the Stichting Astma Bestrijding for their financial support.

\section{References}

1. Floyer Sir J. A treatise of the asthma. London, Wilkin and Innis, 1698.

2. Kattan M, Keens TG, Mellis CM, Levison H. The response to exercise in normal and asthmatic children. J Pediatr 1978; 92: 718-721.

3. Custovic A, Arifhodzic N, Robinson A, Woodcock A. Exercise testing revisited: the response to exercise in normal and atopic children. Chest 1994; 105: 1127-1132.

4. Cypcar D, Lemanske RF. Asthma and exercise. Clin Chest Med 1994; 15: 351-368.

5. Wiens L, Sabath R, Ewing L, Gowdamarajan R, Portnoy J, Scagliotti D. Chest pain in otherwise healthy children and adolescents is frequently caused by exercise-induced asthma. Pediatrics 1992; 90: 350-353.

6. Makker HK, Holgate ST. Review: mechanisms of exercise-induced asthma. Eur J Clin Invest 1994; 24: 571-585.

7. Finnerty JP, Holgate ST. Evidence for the roles of histamine and prostaglandins as mediators in exercise-induced asthma: the inhibitory effect of terfenadine and flurbiprofen alone and in combination. Eur Respir J 1990; 3: 540-547.

8. Manning PJ, Watson RM, Margolskee DJ, Williams VC, Schwartz JI, O'Byrne PM. Inhibition of exercise-induced bronchoconstriction by MK-571, a potent leukotriene $\mathrm{D}_{4}$ receptor antagonist. N Engl J Med 1990; 323: 1736-1739.

9. Bierman CW, Spiro SG, Petheram I. Late response to exercise-induced asthma. J Allergy Clin Immunol 1980; 65: 206.

10. Durham SR. The significance of late responses in asthma. Clin Exp Allergy 1991; 21: 3-7.

11. Lee TH, Nagakura T, Papageorgiou N, Iikura Y, Kay AB. Exercise-induced late asthmatic reactions with neutrophil chemotactic activity. N Engl J Med 1983; 308: 1502-1505.

12. Bierman CW, Spiro SG, Petheram I. Characterization of the late asthmatic response in exercise-induced asthma. J Allergy Clin Immunol 1984; 74: 701-706.

13. Iikura $Y$, Inui H, Nagakura T, Lee TH. Factors predisposing to exercise-induced late asthmatic responses. J Allergy Clin Immunol 1985; 75: 285-289.
14. Boner A, Niero E, Antolini I, Warner JO. Biphasic (early and late) asthmatic responses to exercise in children with severe asthma, resident at high altitude. Eur J Pediatr 1985; 144: 164-166.

15. Boulet L-P, Legris C, Turcotte H, Hebert J. Prevalence and characteristics of late asthmatic responses to exercise. J Allergy Clin Immunol 1987; 80: 655-662.

16. Speelberg B, Van den berg NJ, Oosthoek CHA, Verhoeff NPLG, Van den Brink WTJ. Immediate and late asthmatic responses induced by exercise in patients with reversible airflow limitation. Eur Respir J 1989; 2: 402-408.

17. Verhoeff NPLG, Speelberg B, Van den Berg NJ, Oosthoek CHA, Stijnen T. Real and pseudo late asthmatic reactions after submaximal exercise challenge in patients with bronchial asthma: a new definition for late asthmatic responses after exercise challenge. Chest 1990; 98: 1194-1199.

18. Dahl R, Henriksen JM. Development of late asthmatic reactions after allergen or exercise challenge tests. Eur J Respir Dis 1980; 61: 320-324.

19. Rubinstein I, Levison H, Slutsky AS, et al. Immediate and delayed bronchoconstriction after exercise in patients with asthma. N Engl J Med 1987; 317: 482-485.

20. Zawadski DK, Lenner KA, McFadden ER. Re-examination of the late asthmatic response to exercise. Am Rev Respir Dis 1988; 137: 837-841.

21. Karjalainen J. Exercise response in 404 young men with asthma: no evidence for a late asthmatic reaction. Thorax 1991; 46: 100-104.

22. Crimi E, Balbo A, Milanese M, Miadonna A, Rossi GA, Brusasco V. Airway inflammation and occurrence of delayed bronchoconstriction in exercise-induced asthma. Am Rev Respir Dis 1992; 146: 507-512.

23. Boner AL, Vallone G, Chiesa M, Spezia E, Fambri L, Sette L. Reproducibility of late phase pulmonary response to exercise and its relationship to bronchial hyperreactivity in children with chronic asthma. Pediatr Pulmonol 1992; 14: 156-159.

24. Lee TH, O'Hickey SP (Editorial). Exercise-induced asthma and late phase reactions. Eur Respir J 1989; 2: 195-197.

25. Stenton SC, Avery AJ, Walters EH, Hendrick DJ. Statistical approaches to the identification of late asthmatic reactions. Eur Respir J 1994; 7: 806-812.

26. American Thoracic Society. Standards for the diagnosis and care of patients with chronic obstructive pulmonary disease (COPD) and asthma. Am Rev Respir Dis 1987; 136: 225-243.

27. Zapletal A, Samanek M, Paul T. Lung function in children and adolescents: methods and reference values. Prog Respir Res 1987; 22: 83-112.

28. Quanjer PhH, Tammeling GJ, Cotes JE, Pedersen OF, Peslin R, Yernault J-C. Standardized lung function testing: lung volumes and forced ventilatory flows. Eur Respir J 1993; 6 (Suppl. 16): 5-40.

29. Anderson SD, Schoeffel RE. Standardization of exercise testing in the asthmatic patient: a challenge in itself. In: Airway Responsiveness. Mississauga, Astra Pharmaceuticals Ltd, 1985; 51-59.

30. Boulet L-P, Turcotte H. Influence of water content of inspired air during and after exercise on induced bronchoconstriction. Eur Respir J 1991; 4: 979-984.

31. Hofstra WB, Sont JK, Sterk PJ, Neijens HJ, Duiverman EJ. Repeatability of exercise-induced asthma using treadmill exercise challenge in asthmatic children. Am J Respir Crit Care Med 1995; 151: A747. 
32. Duiverman EJ, Neijens HJ, van der Snee van Smaalen M, Kerrebijn KF. Comparison of forced oscillometry and forced expirations for measuring dose-related responses to inhaled methacholine in asthmatic children. Bull Eur Physiopathol Respir 1986; 22: 433-436.

33. White MV, Slater JE, Kaliner MA. Histamine and asthma. Am Rev Respir Dis 1987; 135: 1165-1176.

34. Kleinbaum DG, Kupper LL, Muller KE. Testing hypotheses in multiple regression. In: Kleinbaum DG, Kupper LL, Muller KE, eds. Applied Regression Analysis and Other Multivariable Methods. Boston, PWS Kent, 1988; pp. 124-143.

35. Cockcroft DW. Nonallergic airway hyperresponsiveness. J Allergy Clin Immunol 1988; 81: 111-119.

36. Sterk PJ, Fabbri LM, Quanjer PhH, et al. Airway responsiveness: standardized challenge testing with pharmacological, physical and sensitizing stimuli in adults. Eur Respir J 1993; 6 (Suppl. 16): 53-83.

37. Argyros GJ, Phillips W, Rayburn DB, Rosenthal RR, Jaeger JJ. Water loss without heat flux in exerciseinduced bronchoconstriction. Am Rev Respir Dis 1993. 147: 1419-1424.

38. O'Byrne PM, Dolovich J, Hargreave FE. State of the art: late asthmatic responses. Am Rev Respir Dis 1987; 136: 740-751.

39. De Monchy JGR, Kauffman HF, Venge P, et al. Bronchoalveolar eoinophilia during allergen-induced late-phase asthmatic reaction. Am Rev Respir Dis 1985; 131: 373-376.

40. Venge P, Dahl R, Peterson CGB. Eosinophil granule proteins in serum after allergen challenge of asthmatic patients and the effects of anti-asthmatic medication. Int Arch Allergy Appl Immunol 1988; 87: 306-312.

41. Mussafi H, Springer C, Godfrey S. Increased bronchial responsiveness to exercise and histamine after allergen challenge in children with asthma. J Allergy Clin Immunol 1986; 77: 48-52.

42. Holgate S. Mediator and cytokine mechanisms in asthma. Thorax 1993; 48: 103-109.

43. O' Byrne PM. Allergen-induced airway hyperresponsiveness. J Allergy Clin Immunol 1988; 81: 119-127.

44. Rabe KF, Jorres R, Magnussen H. The effect of 10, 50 and $200 \mu \mathrm{g}$ inhaled fenoterol on exercise induced asthma. Clin Exp Allergy 1993; 23: 440-445.

45. Morton AR, Ogle SL, Fitch KD. Effects of nedocromil sodium, cromolyn sodium, and a placebo in exerciseinduced asthma. Ann Allergy 1992; 68: 143-148.

46. Kiviloog J. The correlation between exercise-induced bronchoconstriction and bronchial methacholine sensitivity in asthma. Pediatrics 1975; 56(Suppl.): 908-909.

47. Waalkens HJ, Van Essen-Zandvliet EEM, Gerritsen J, Duiverman EJ, Kerrebijn KF, Knol K and the Dutch CNSLD Study Group. The effect of an inhaled corticosteroid (budesonide) on exercise-induced asthma in children. Eur Respir J 1993; 6: 652-656. 